Research Article

\title{
Comparative Study on the Catalytic Performance of a 13X Zeolite and its Dealuminated Derivative for Biodiesel Production
}

\author{
Balqees A. Alshahidy, Ammar S. Abbas* \\ Department of Chemical Engineering, College of Engineering, University of Baghdad, Iraq.
}

Received: 13 th June 2021; Revised: 11 th August 2021; Accepted: $12^{\text {th }}$ August 2021

Available online: 14th August 2021; Published regularly: December 2021

Abstract

Natural kaolin clay was used to successfully prepare $13 \mathrm{X}$ zeolite catalysts, which were modified by dealumination with citric acid. Acid leaching eliminates impurities and aluminum, and improves the Si/Al ratio of the zeolite framework. The X-ray diffraction (XRD) patterns of both the original and modified 13X zeolites were the same, indicating that the crystalline frameworks were not destroyed during the dealumination process. X-ray fluorescence data of the dealuminated 13X zeolite showed an improved Si/Al ratio. Also, Atomic Force Microscopy (AFM) was used for the characterization of the catalysts. The catalytic performance of the original and modified catalysts was tested in the esterification reaction of oleic acid in a batch reactor. A higher conversion of oleic acid was obtained using the modified 13X zeolite. The resulting experimental data from the esterification reactions were fitted to the heterogeneous Langmuir-Hinshelwood-Hougen-Watson (LHHW) kinetic model to determine the rates of reaction. The results of the reaction kinetics showed an increase in the rate of reaction velocity and a distinct decrease in the activation energy when using the modified zeolite, indicating that employing the modified catalyst will give a higher conversion over a shorter time through a reaction with less sensitivity to temperature.

Copyright (C) 2021 by Authors, Published by BCREC Group. This is an open access article under the CC BY-SA License (https://creativecommons.org/licenses/by-sa/4.0).

Keywords: 13X zeolite; characterization; dealumination; heterogeneous catalysis; esterification kinetics; biodiesel

How to Cite: B.A. Alshahidy, A.S. Abbas (2021). Comparative Study on the Catalytic Performance of a 13X Zeolite and its Dealuminated Derivative for Biodiesel Production. Bulletin of Chemical Reaction Engineering \& Catalysis, 16(4), 763-772 (doi:10.9767/bcrec.16.4.11436.763-772

Permalink/DOI: https://doi.org/10.9767/bcrec.16.4.11436.763-772

\section{Introduction}

Energy plays an important role in transportation, industrial sectors, and power generation; therefore, energy has become an essential requirement for maintaining and improving living standards [1]. The need for fossil fuels has significantly increased over the past few decades due to rising economies and worldwide declines in fossil fuel reserves [2]. The environmental impact of fossil fuel emissions, fossil fuel depletion, rising oil prices, and growing energy demands

*Corresponding Author.

Email: ammarabbas@coeng.uobaghdad.edu.iq (A.S. Abbas); Telp: +9647901307270 has stimulated interest among academics, scientists, and industrialists in developing alternative sustainable fuel. Such alternative fuels should be eco-friendly, economically feasible, efficient, and easily constructed [3]. One example is biodiesel, which is non-toxicity, biodegradability, suitable for sensitive environments, and its greenhouse gas emissions can be controlled because most of its feedstock is renewable [4].

Biodiesel is produced by trans-esterifying triglycerides that generates alkyl esters and glycerin, or by esterifying fatty acids to give alkyl esters and water. Both processes are done with short-chain alcohols, such as ethanol [5] or methanol [6], in the presence of an acid or base 
catalyst [7]. Biodiesel can be chemically defined as a mixture of ethyl esters with long-chain fatty acids obtained from renewable sources, such as vegetable oils [8], animal fats, sunflower seeds [9]. Such oils and fats may contain about $20 \%$ free fatty acids (FFAs), but an ideal amount should not exceed 1\% because the saponification of FFAs reduces the fatty acid alkyl ester yield [10]. Therefore, when using raw materials with high FFA content, an esterification reaction is required to produce biodiesel, using supercritical, enzyme, heterogeneous, or homogeneous acid catalysts [11].

Esterification is a significant, alternative process to transesterification. Although the availability of natural, raw materials rich in triglycerides makes transesterification more viable, esterification reactions employ materials with FFA-rich residues and by-products, allowing them to deal with industrial biomass [12]. Esterification is the reaction between a fatty acid and an alcohol that occurs in the presence of an acid catalyst. Traditionally, biodiesel is produced with homogeneous catalysts (e.g. sulfuric acid), which are strong mineral acids that produce high reaction conversions [13] but erode equipment. Therefore, the homogeneous catalysts can be replaced by heterogeneous catalysts.

Heterogeneous acid catalysts produce biodiesel in an economically feasible way. They slowly convert fats or oils into biodiesel and are reusable; thus, the production cost is low and the catalysts have high activity, are stable, and it is easy to separate from the products [11]. Various heterogeneous acid catalysts are used, the conventional ones being solid resin, enzymes, and zeolites. Several types of zeolites have been used to produce biodiesel: zeolite beta [14], NaY zeolite [15], HY zeolite [16], ZSM-5 [17], mordenite [18], FAU-type zeolite [19], [20], ZSM-5 modified with citric acid [21], modified mordenite [22], and 13X zeolite [23] that gives a low conversion rate due to its low $\mathrm{Si} / \mathrm{Al}$ ratio. All of these zeolites are considered heterogeneous catalysts.

Several post-synthesis treatments for zeolites were used to raise their $\mathrm{Si} / \mathrm{Al}$ ratio, which would improve their catalytic properties. The dealumination processes, including acid leaching and steaming, change the quantity (and ul- timately the strength) of Brønsted acid sites, which may produce Lewis sites when the aluminum frameworks are removed. Simultaneously, meso-porosity is generated that promotes the accessibility of the acid sites remaining in the framework, which has been particularly relevant when large molecule transformations were tested over zeolite [24].

This work prepared 13X zeolite from natural kaolin clay, which was subsequently modified by dealumination with citric acid to improve its $\mathrm{Si} / \mathrm{Al}$ ratio and its ability to convert oleic acid into ethyl oleate via esterification with ethanol. The influence of reaction temperature and time on oleic acid conversion is discussed herein, and the kinetics of the batch esterification reactions were studied to compare the performance of the original and modified zeolite catalysts with those of other zeolite catalysts.

\section{Materials and Method}

\subsection{Preparation of 13X Zeolite}

Natural kaolin clay was converted to active kaolin (metakaolin) by calcination at $550{ }^{\circ} \mathrm{C}$ for $2 \mathrm{~h}$ in an electric heater [25]. Table 1 shows the chemical composition of kaolin clay. Then the metakaolin was ground and sieved until a particle size of $\leq 75$ microns was achieved. The reactant mixture expressed in terms of oxide mole ratio which has a composition of [26]:

\section{$\left(\mathrm{SiO}_{2} / \mathrm{Al}_{2} \mathrm{O}_{3}\right) /\left(\mathrm{Na}_{2} \mathrm{O} / \mathrm{SiO}_{2}\right) /\left(\mathrm{H}_{2} \mathrm{O} / \mathrm{Na}_{2} \mathrm{O}\right): 4 / 1 / 40$}

Metakaolin and sodium trisilicate were mixed in a two-necked round bottom flask with sodium hydroxide solution (9 wt.\%). The mixture was stirred for $72 \mathrm{~h}$ at $70^{\circ} \mathrm{C}$ with a variable-speed, stainless-steel paddle mixer equipped with a motor driven by a relatively medium revolution (Voss Instrument Ltd. Type SG/PA/ST). An electrical mantle heater was used to heat the flask, while variable input voltage was used to control the temperature of the solution. Upon completion of the reaction, the mixture was decanted and washed with deionized water to remove any excess alkali. Once a $\mathrm{pH}$ of 10 was reached, the product was filtered with a Buchner funnel attached to a vacuum pump (Edward vacuum pump, model

Table 1. Chemical composition of local kaolin clay.

\begin{tabular}{ccccccc}
\hline Component & $\mathrm{SiO}_{2}$ & $\mathrm{Al}_{2} \mathrm{O}_{3}$ & $\mathrm{Fe}_{2} \mathrm{O}_{3}$ & $\mathrm{Na}_{2} \mathrm{O}$ & $\mathrm{TiO}_{2}$ & L.O.I* $^{*}$ \\
\hline Wt. $\%$ & 50.84 & 33.3 & 0.96 & 0.09 & 1.34 & 12.66 \\
\hline
\end{tabular}

*L.O.I loss on ignition 
EiM5, serial $0146 \mathrm{~g}$ ), dried at $120^{\circ} \mathrm{C}$ for $12 \mathrm{~h}$ in an electric oven (Tecnoformal Ltd., Max. Temp. $250{ }^{\circ} \mathrm{C}$ ), and then milled using a centrifuge ball mill (Type RETCH, S2) equipped with seven steel balls to grind the zeolite into a fine powder.

\subsection{Modification of 13X Zeolite}

Ten grams of the original $13 \mathrm{X}$ zeolite was treated with $150 \mathrm{~mL}$ of $0.1 \mathrm{~N}$ citric acid solution at $75{ }^{\circ} \mathrm{C}$ for $3 \mathrm{~h} \mathrm{[27].} \mathrm{The} \mathrm{final} \mathrm{product} \mathrm{was}$ subsequently recovered by vacuum filtration, washed with deionized water to eliminate any complexes of aluminum that may have formed, and then dried in an electric oven at $100^{\circ} \mathrm{C}$. Finally, the solid sample was calcined at $500{ }^{\circ} \mathrm{C}$ for $3 \mathrm{~h}$.

\subsection{Characterization of Catalysts}

The structural characterization of the original and modified 13X zeolite samples was carried out by X-ray diffraction (XRD) using a D2 PHASER diffractometer (Bruker AXS, Karlsruhe-Germany) using $\mathrm{Cu}-\mathrm{K} \alpha$ radiation with a nickel filter $(\lambda=1.541874 \AA)$. The diffraction patterns were obtained within the $2 \theta$ range of $3^{\circ}$ and $65^{\circ}$ with a scan speed of 0.04 degrees per second. The X-ray fluorescence (XRF) analysis was performed on a Spectro XEPOS spectrometer (Germany) with X-LAB Pro software to determine the chemical composition of the sample, i.e., the $\mathrm{Si} / \mathrm{Al}$ molar ratio. BrunauerEmmett-Teller (BET) surface area and pore volume of the original and modified $13 \mathrm{X}$ zeolite were measured by a Flowing Gas Surface Area Analyzers (SA-9600 Series, HORIBA Scientific, Japan). Atomic Force Microscopy (AFM) was used to determine the particle size and morphology of the catalysts at the nano-level and

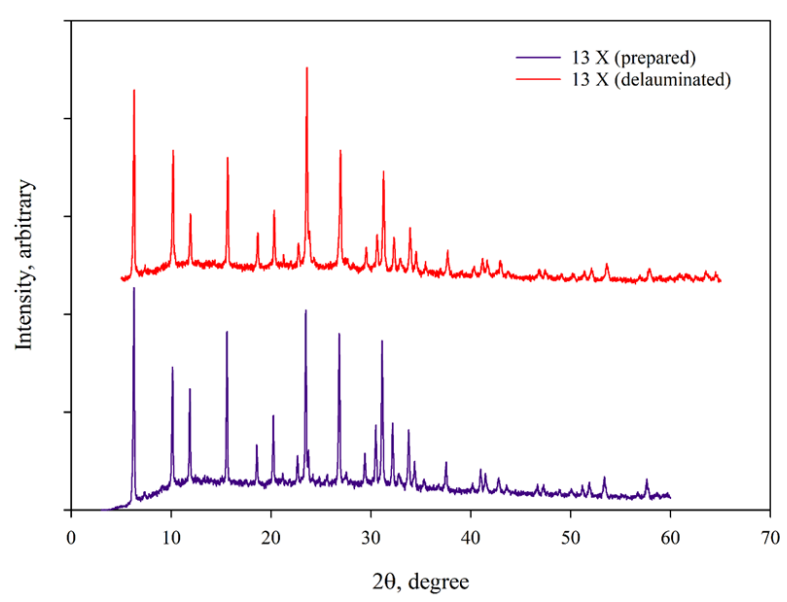

Figure 1. XRD characterization result of the prepared and dealuminated 13X zeolite. was performed using an SPM-AA3000 (Angstrom Advanced Inc., Stoughton, Wisconsin, USA). The morphology of the original and modified 13X zeolite was studied by scanning electron microscopy (SEM, Inspect S50, FEI, USA).

\subsection{Catalysts Testing for Oleic Acid Esterifica-} tion

Esterification reaction was performed in a 3-neck $500 \mathrm{~mL}$ round bottom flask fitted with a stopper, water-cooled condenser, and a thermometer to measure the solution temperature. The reaction mixture was stirred and heated using an electromagnetic hot plate. An ethanol to oil molar ratio of $6: 1$ and 5 wt.\% (relative to oleic acid) of the catalyst was used in all the experiments. The reaction temperature ranged from 30 to $70{ }^{\circ} \mathrm{C}$ [13] and the reaction time was up to $180 \mathrm{~min}$.

The reactor was loaded with $150 \mathrm{~mL}$ of oleic acid and the desired amount of ethanol. Since ethanol and oil are immiscible, maintaining constant agitation at $300 \mathrm{rpm}$ is necessary to increase the contact surface. After the reaction mixture was heated to the desired reaction temperature, the catalyst was added. At different intervals, $2 \mathrm{~mL}$ of the reaction mixture was withdrawn and centrifuged (Griffin and George, Loughborough, Britain) for $10 \mathrm{~min}$ at $3000 \mathrm{rpm}$ to improve the phase separation. The top layer was titrated with $0.1 \mathrm{~N} \mathrm{KOH}$ using phenolphthalein as an indicator to obtain the acid value (AV), as shown in Equation (1).

$$
A V=\frac{m l \text { of } \mathrm{KOH} \times N \times 56.1}{\text { weight of sample }}
$$

Oleic acid conversion for each quantity of the catalyst can be calculated using Equation (2) $[13,16]$.

$$
\text { Conversion, } \%=\frac{A V_{t o}-A V_{t}}{A V_{t o}} \times 100
$$

where $A V_{\text {to }}$ is the initial acid value (i.e. the acid value of oleic acid: 196.35) and $A V_{\mathrm{t}}$ is the acid value of the supernatant layer at time $t$.

\section{Results and Discussion}

\subsection{Catalysts Characterization}

XRD patterns of the original and modified 13X zeolite catalysts at diffraction peaks between $3^{\circ}$ and $65^{\circ}(2 \theta)$ are shown in Figure 1 (blue and red lines, respectively). The original 13X zeolite pattern was similar to those of standard 13X zeolites [28] and the modified 13X zeolite. All XRD patterns obtained of the 
original and modified zeolite indicate that both catalysts possess highly crystalline structures, which means that the crystalline frameworks were not destroyed during the modification process [29]. However, new diffraction peaks were observed in the dealuminated catalyst pattern (Figure 1, red line), indicating the formation of various crystalline phases. Furthermore, the weaker intensities of the associated peaks indicate that during the modification process the crystalline grain size decreased, which can be explained by calculating the average crystal size of the original and modified 13X zeolite using Scherrer's equation. The calculated average crystallite size for the original and modified $13 \mathrm{X}$ zeolite were $5.9468 \AA$ and $5.9244 \AA$, respectively.

The crystallinity percentage for both the original and modified $13 \mathrm{X}$ zeolite, with respect to the standard $13 \mathrm{X}$ zeolite, were $87.71 \%$ and $85.80 \%$, respectively, according to Equation (3) [28].

(a)

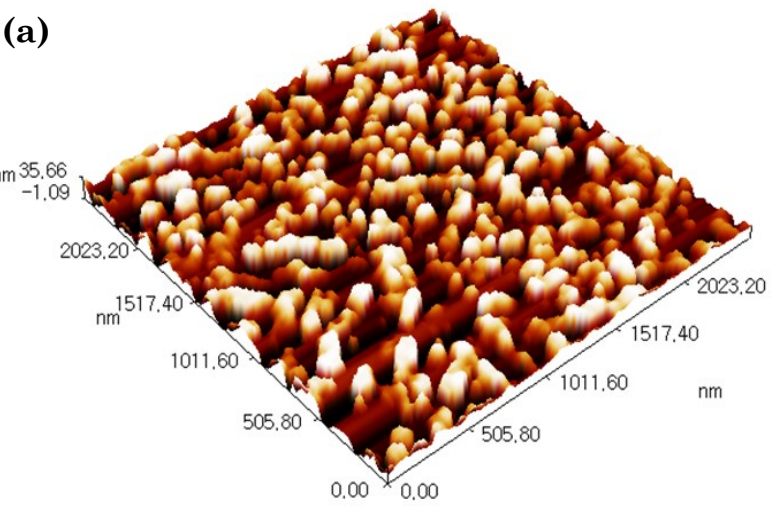

Average crystallinity, $\%=\frac{\sum I_{\text {int,crystal }}}{\sum I_{\text {int,crystal }}+\sum I_{\text {int,amorphous }}} \times 100$

The Si/Al ratio for the original 13X zeolite was 1.74 , which is in a good agreement with the value obtained by Breck [30]. Chemical composition changes are evident in the modified $13 \mathrm{X}$ zeolite, which is ascribed to its improved $\mathrm{Si} / \mathrm{Al}$ ratio via dealumination. The $\mathrm{Si} / \mathrm{Al}$ ratio of the modified 13X zeolite was 4.72 , nearly 2.7 times that of the original 13X zeolite. An improved $\mathrm{Si} / \mathrm{Al}$ ratio occurs due to the exchange of cations existing on the catalyst surface $\left(\mathrm{Na}^{+}, \mathrm{Ca}^{2+}\right.$, $\mathrm{Mg}^{2+}$, etc.) with a proton from the solution. This exchange forms hydroxyl bridges, which are converted to $\mathrm{SiOH}$ as a result of the reaction between the solution $\mathrm{H}^{+}$and the framework $\mathrm{Al}$ [31,32].

AFM was used to determine the particle size distribution and topography of both the original and modified 13X zeolite. The AFM images in Figure 2 ( $a$ and $b$ ) displayed the three-dimensional surface profiles of the cata-

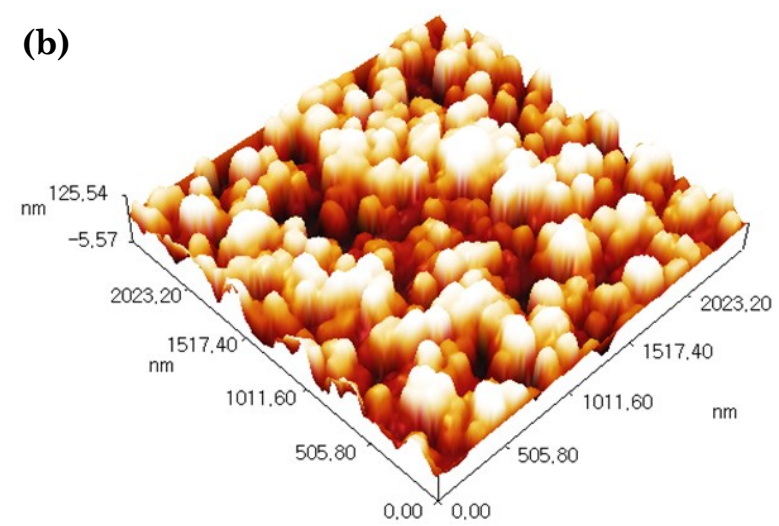

Figure 2. Three-dimensional surface profile of AFM images of (a) original - and (b) dealuminated 13X zeolite.
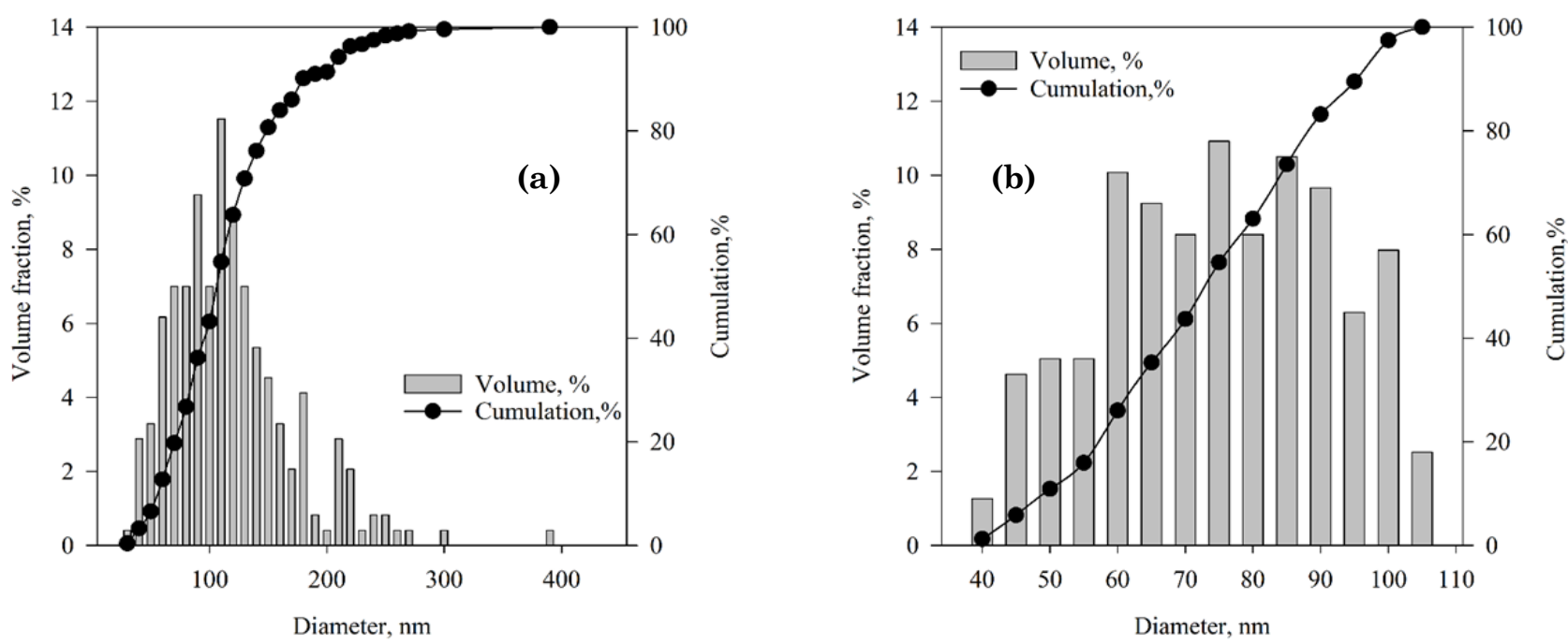

Figure 3. Granularity cumulation distribution chart of (a) the original and (b) modified 13X zeolite. 
lysts, which provided detailed observations of nanometer size events at the crystal surface and the layer growth of the zeolite crystals. From the AFM test, we determined that the average roughness of the original $13 \mathrm{X}$ zeolite was $9.18 \mathrm{~nm}$ with a $10.6 \mathrm{~nm}$ root mean square, while the modified 13X zeolite had an average roughness of $28.6 \mathrm{~nm}$ with a $34 \mathrm{~nm}$ root mean square. These values confirm that the surface of the original catalyst was covered with metal oxides (impurities) that reduced its average roughness, and these impurities were removed by the dealumination process. The negative surface skewness values of -0.000799 and -0.361 for the original and modified $13 \mathrm{X}$ zeolite, respectively, indicate that their surfaces consisted of valleys [33], where a highly negative skewness value implies that the surface contains numerous local maxima above the mean line [34]. If the kurtosis parameter is added, an even better representation of a rough surface can be obtained. This parameter is a description of the surface peakedness, and it was equal to 1.8 and 2.18 for the original and modified 13X zeolite, respectively. For reference, a kurtosis value $<3$ suggests a broad morphology [35]. The granularity accumulation distribution shown in Figure 3 (a and b) and reveals that the average particle size for the original 13X zeolite was $72.39 \mathrm{~nm}$, where $\leq 10 \%$ of the particles had a diameter of $45 \mathrm{~nm}, \leq 50 \%$ of the particles had a diameter of $70 \mathrm{~nm}$, and $\leq 90 \%$ of the particles had a diameter of $95 \mathrm{~nm}$. Meanwhile, the average particle size for the modified 13X catalyst was $113.37 \mathrm{~nm}$, where $\leq 10 \%$ of the particles had a diameter of $50 \mathrm{~nm}$, $\leq 50 \%$ of the particles had a diameter of 100 $\mathrm{nm}$, and $\leq 90 \%$ of the particles had a diameter of $170 \mathrm{~nm}$. This difference in diameters may be due to the processes of desilication and dissolution of the zeolite framework that begins with the $\mathrm{Si}-\mathrm{O}-\mathrm{Si}$ linkages [36], which would decrease the crystallinity. Generally, measuring particle size by AFM techniques is considered more reliable.

\subsection{Influence of Reaction Temperature and Time on Oleic Acid Conversion}

Esterification reactions can occur at different temperatures, and studying the effect of reaction temperature on heterogeneous catalytic reactions is important because this information helps calculate the activation energy of these reactions. In addition, the constants of the reaction rate are strong, temperature-dependent functions. Figure 4 (a and b) presents the results obtained for oleic acid conversion with time at various temperatures using $5 \mathrm{wt}$. \% of either the original or modified $13 \mathrm{X}$ zeolite with an ethanol/oleic acid (6:1) mixture. This molar ratio and amount of catalyst are optimal values reported by Abbas and Abbas [15]. As expected, oleic acid conversions increased with reaction time at all temperatures and it can be observed that during the first $90 \mathrm{~min}$ of the reaction the change in the conversion is high and then it stabilizes. For the modified 13X zeolite, the change is rapid during the first $10 \mathrm{~min}$. After that, the change is negligible until it stabilizes
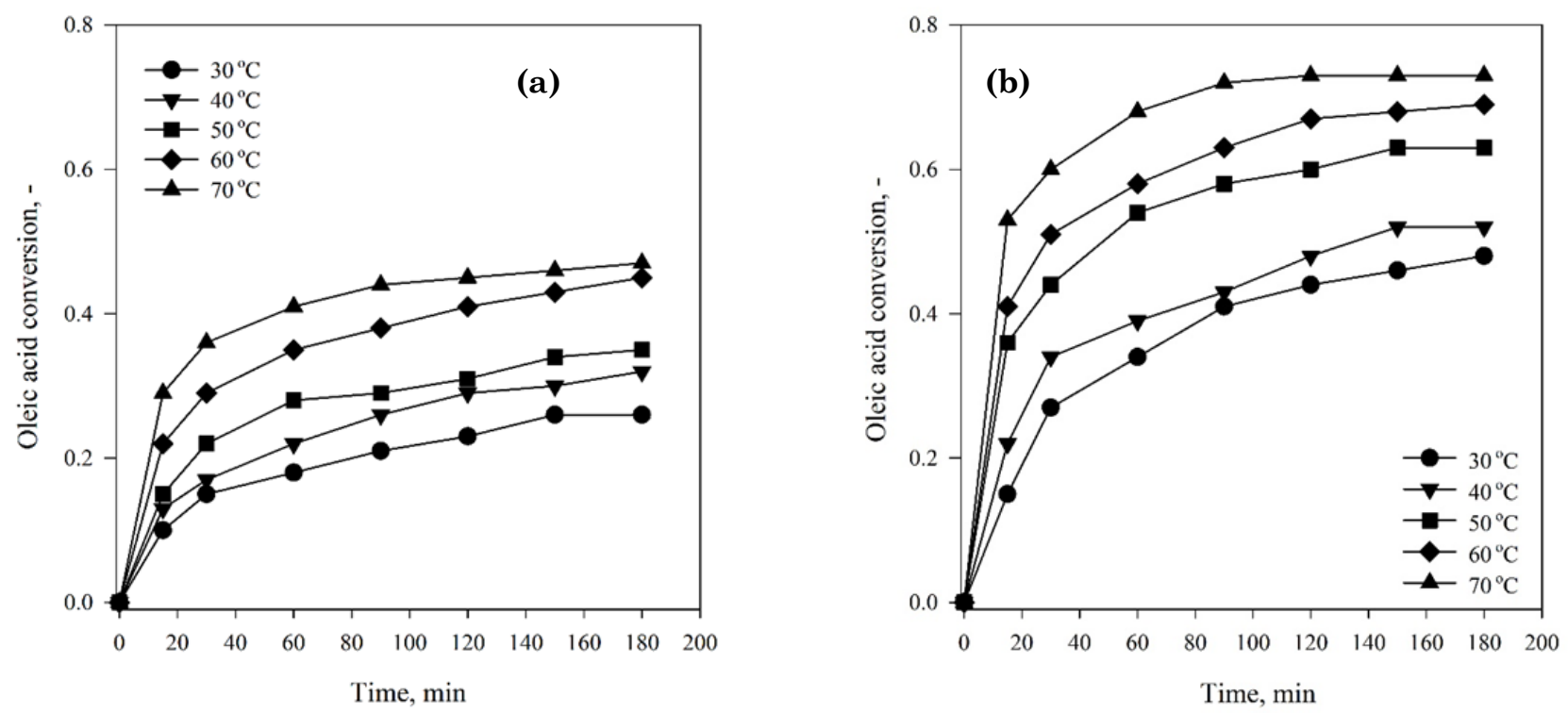

Figure 4. Effect of reaction temperature on oleic acid conversion over (a) the original and (b) modified $13 \mathrm{X}$ zeolite. 
(Figure 4 (b)). Increasing the reaction temperature had a favorable effect on the conversion of oleic acid. The oleic acid highest conversion over the original $13 \mathrm{X}$ zeolite was only $47 \%$ (Figure 4 (a)). Improvement in the conversion of oleic acid was observed when the modified $13 \mathrm{X}$ zeolite was employed, exhibiting a conversion of $73 \%$, the highest conversion achieved in this study (Figure 4 (b)). These results show that zeolites provide better conversions for esterification reactions when they are dealuminated with citric acid [37]. An increased conversion of oleic acid with the modified zeolite could be ascribed to several factors. The quantity and intensity of acid sites, which increases with increasing the ratio of $\mathrm{Si} / \mathrm{Al}$, may play an important role in oleic acid conversion. In addition, citric acid dealumination leads to a higher external surface area, which consequently increases the number of acid sites available to oleic acid molecules [38].

\section{Heterogeneous Reaction Kinetics of Oleic Acid Esterification}

Esterification of oleic acid is treated as a heterogeneous catalytic reaction because the reaction mixture contains more than one phase: the catalyst is a solid and the reactants and products are liquids. The LangmuirHinshelwood-Hougen-Watson (LHHW) model is used to express the esterification reaction with many heterogeneous catalysts used in this reaction [39]. This kinetic model assumes that both the oleic acid and ethanol molecules are adsorbed onto the catalyst surface before the surface reaction. The final stage of the mechanism involves desorption of both products, ethyl oleate and water. If the surface reaction is assumed to be the rate-controlling step, the LHHW model equation for the reaction of oleic acid with ethanol is first derived in terms of surface concentration of the adsorbed species and vacant sites:

$$
O A+E t O H \underset{k_{s}^{\prime}}{\stackrel{k_{s}}{\rightleftharpoons}} E O+W
$$

According to the mechanism, the surface reaction takes place between adsorbed oleic acid (OA) and adsorbed ethanol (EtOH), producing adsorbed ethyl oleate (EO) and adsorbed water (W). The rate of the surface reaction is given in Equation (6), where $K_{s}$ is the ratio of $k_{s}$ to $k_{s}^{\prime}$ (Eq. 7).

$$
-r_{O A_{s}}=k_{s}\left(C_{O A_{s}} C_{E t O H_{s}}-\frac{1}{K_{s}} C_{E O_{s}} C_{W_{s}}\right)
$$

$$
K_{s}=\frac{k_{s}}{k_{s}^{\prime}}
$$

As all other steps are considered to be in balance, the concentration of each adsorbed species can therefore be obtained:

$$
K_{i}=\frac{C_{i_{s}}}{C_{i} C_{v}}
$$

where $i$ is $\mathrm{OA}$, EtOH, EO, or W. Then, the adsorbed phase concentrations can be written as:

$$
\begin{aligned}
& C_{O A_{s}}=K_{O A} C_{O A} C_{v} \\
& C_{E t O H_{s}}=K_{E t O H} C_{E t O H} C_{v} \\
& C_{E O_{s}}=K_{E O} C_{E O} C_{v} \\
& C_{W_{s}}=K_{W} C_{W} C_{v}
\end{aligned}
$$

Substituting all these values (Eq. (9) to (12)) into Equation (6) gives:

$-r_{O A_{s}}=k_{s}\left(K_{O A} C_{O A} C_{v} K_{E t O H} C_{E t O H} C_{v}-\frac{1}{K_{s}} K_{E O} C_{E O} C_{v} K_{W} C_{W} C_{v}\right)$

Therefore,

$$
\begin{aligned}
C_{O A_{0}}= & C_{O A_{s}}+C_{E t O H_{s}}+C_{E O_{s}}+C_{W_{s}}+C_{v} \\
C_{O A_{0}}= & K_{O A} C_{O A} C_{v}+K_{E t O H} C_{E t O H} C_{v}+K_{E O} C_{E O} C_{v} \\
& +K_{W} C_{W} C_{v}+C_{v}
\end{aligned}
$$

which can be simplified into:

$C_{O A_{0}}=C_{v}\left(K_{O A} C_{O A}+K_{E t O H} C_{E t O H}+K_{E O} C_{E O}+K_{W} C_{W}+1\right)$

Finally, solving for $C_{v}$ gives:

$$
C_{v}=\frac{C_{O A}}{\left(K_{O A} C_{O A}+K_{E t O H} C_{E t O H}+K_{E O} C_{E O}+K_{W} C_{W}+1\right)}
$$

For the reaction $\mathrm{OA}+\mathrm{EtOH} \leftrightarrow \mathrm{EO}+\mathrm{W}$, the overall equilibrium constant is:

$$
K=\frac{C_{E O} C_{W}}{C_{O A} C_{E t O H}}
$$

All concentrations correspond to the equilibrium conditions. Substituting Equations (9) (12) into Equation (18) gives:

$$
K=\frac{\left(\frac{C_{E O_{s}}}{K_{E O} C_{v}}\right)\left(\frac{C_{W_{s}}}{K_{W} C_{v}}\right)}{\left(\frac{C_{O A_{s}}}{K_{O A} C_{v}}\right)\left(\frac{C_{E t O H_{s}}}{K_{E t O H} C_{v}}\right)}
$$

which can be simplified into:

$$
K=\frac{C_{E O_{s}} C_{W_{s}}}{C_{O A_{s}} C_{E t O H_{s}}} \cdot \frac{K_{O A} K_{E t O H}}{K_{E O} K_{W}}
$$

Since,

$$
K_{s}=\frac{C_{E O_{s}} C_{W_{s}}}{C_{O A_{s}} C_{E t O H_{s}}}
$$




$$
K=\frac{K_{O A} K_{E t O H}}{K_{E O} K_{W}} \cdot K_{s}
$$

Substituting Equations (9) - (12) into Equation (6) gives:

$$
-r_{O A_{s}}=k_{s}\left(K_{O A} C_{O A} C_{v} K_{E I O H} C_{E O H H} C_{v}-\frac{1}{K_{s}} K_{E O} C_{E O} C_{v} K_{W} C_{W} C_{v}\right)
$$

which can be rewritten as:

$-r_{O A, s}=k_{s} K_{O A} K_{E O O H} C_{O A}^{2} \frac{\left(C_{O A} C_{E O O H}-\frac{1}{K_{s}} C_{E O} C_{W W}\right)}{\left(1+K_{O A} C_{O A}+K_{E O H} C_{E O H}+K_{E O} C_{E O}+K_{W} C_{W}\right)^{2}}$

The LHHW model (Eq. 24) was solved numerically by minimizing the Chi-squared statistic $\left(\chi^{2}\right)$ and maximizing the correlation coefficient $\left(\mathrm{R}^{2}\right)$, as shown in Equations (25) and (26),

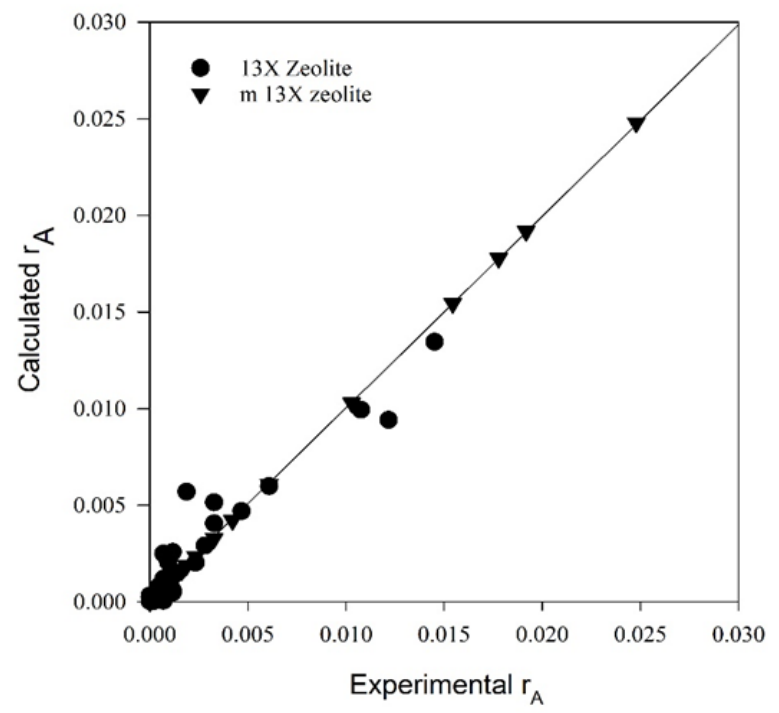

Figure 5. Plot of experimental and calculated reaction rates for the original and modified $13 \mathrm{X}$ zeolites. respectively.

$$
\begin{gathered}
\chi^{2}=\sum_{i=1}^{n} \frac{\left(r_{i O A_{\mathrm{exp}}}-r_{i O A_{c a l}}\right)^{2}}{r_{i O A_{c a l}}} \\
R^{2}=\frac{\left(\sum_{i=1}^{n}\left(r_{i O A_{\mathrm{exp}}}-\bar{r}_{i O A_{\mathrm{exp}}}\right)\left(r_{i O A_{c a l}}-\bar{r}_{i O A_{c a l}}\right)\right)}{\sum_{i=1}^{n}\left(r_{i O A_{\mathrm{exp}}}-\bar{r}_{i O A_{\mathrm{exp}}}\right)^{2} \times \sum_{i=1}^{n}\left(r_{i O A_{c a l}}-\bar{r}_{i O A_{c a l}}\right)^{2}}
\end{gathered}
$$

Statistical analysis for the experimental rates (Exp. $r_{A}$ ) versus the calculated rates (Cal. $r_{A}$ ) obtained from the LHHW model is shown in Figure 5. It can be observed that there is an excellent agreement between the calculated and experimental values of the rates for all the esterification reactions with modified $13 \mathrm{X}$ zeolite. This was not observed for the reactions using the original $13 \mathrm{X}$ zeolite.

Regression statistics for the original and modified 13X zeolites are shown in Table 2, where the mean rates for the experimental and calculated work values of each catalyst were close. However, when comparing the mean rates of the original and modified catalyst, differences are evident. The mean rate of reaction over the original catalyst was 0.0022 while the mean rate over the modified catalyst was 0.0036 . This shows that the average rate was improved when using the modified 13X zeolite, resulting in a more rapid esterification reaction.

Tables 3 and 4 present the results of the analyses using the LHHW kinetic model fitting, where $\mathrm{R}^{2}$ values are also provided. In these tables, $k_{\mathrm{s}}$ represents surface reaction rate constant, $K_{\mathrm{S}}$ represents the equilibrium surface

Table 2. Regression statistics of the original and modified 13X zeolites.

\begin{tabular}{lccccc}
\hline Catalyst & \multicolumn{2}{c}{ Original 13X zeolite } & & \multicolumn{2}{c}{ Modified 13X zeolite } \\
\cline { 2 - 3 } \cline { 5 - 6 } & Exp. $r_{\mathrm{A}}$ & Calc. $r_{\mathrm{A}}$ & & Exp. $r_{\mathrm{A}}$ & Calc. $r_{\mathrm{A}}$ \\
\hline Mean & 0.0022 & 0.0022 & & 0.0036 & 0.0036 \\
Variance & $1.2317 \times 10^{-5}$ & $1.1061 \times 10^{-5}$ & & $3.9083 \times 10^{-5}$ & $3.0390 \times 10^{-5}$ \\
$\mathrm{R}^{2}$ & \multicolumn{2}{c}{0.9018} & & \multicolumn{2}{c}{0.8817} \\
Standard Error & \multicolumn{2}{c}{0.0011} & & \multicolumn{2}{c}{0.0026} \\
Observation & \multicolumn{2}{c}{35} & & \multicolumn{2}{c}{34} \\
\hline
\end{tabular}

Table 3. Surface reaction rate constants and adsorption equilibrium constants at different reaction temperatures obtained from model Equation (24) for the original 13X zeolite.

\begin{tabular}{cccccccc}
\hline Temperature (K) & $\begin{array}{c}k_{\mathrm{S}} \\
\text { (gcat/L.mol.s) }\end{array}$ & $K_{\mathrm{S}}$ & $K_{\mathrm{OA}}$ & $K_{\mathrm{EtOH}}$ & $K_{\mathrm{EO}}$ & $K_{\mathrm{W}}$ & $\mathrm{R}^{2}$ \\
\hline 303 & 0.0286 & 8.87 & 0.29 & 0.07 & 0.07 & 31.30 & 0.9781 \\
313 & 0.0340 & 32.91 & 0.31 & 0.07 & 0.33 & 31.30 & 0.9740 \\
323 & 0.2286 & 10.95 & 0.28 & 0.07 & 0.12 & 31.30 & 0.9366 \\
333 & 0.3060 & 10.90 & 0.27 & 0.07 & 0.11 & 31.30 & 0.7724 \\
343 & 0.6360 & 8.87 & 0.42 & 0.07 & 0.07 & 31.30 & 0.9440 \\
\hline
\end{tabular}


reaction rate constant for the esterification reaction, and $K_{\mathrm{OA}}, K_{\mathrm{EtOH}}, K_{\mathrm{EO}}$, and $K_{\mathrm{W}}$ represent the adsorption equilibrium constant of OA, ethanol, EO, and water, respectively. It can be observed that the $k_{\mathrm{S}}, K_{\mathrm{S}}, K_{\mathrm{OA}}$, and $K_{\mathrm{EtOH}}$ values increased for the reactions with the modified $13 \mathrm{X}$ zeolite, while the $K_{\mathrm{EO}}$ and $K_{\mathrm{W}}$ values remained constant when both the original and modified 13X zeolite were used.

Arrhenius plots [40] were used to determine then the activation energies (E) of esterification reactions over the original and modified $13 \mathrm{X}$ zeolites (Figure 6). The activation energy for the esterification reaction with the original $13 \mathrm{X}$ zeolite was $72.64 \mathrm{~kJ} / \mathrm{mol}$, while that of the reaction with the modified $13 \mathrm{X}$ zeolite was lower, at a value of $34.76 \mathrm{~kJ} / \mathrm{mol}$. This implies that the reaction became less sensitive to temperature when the modified catalyst was used, which improves the expected quantity of production. For the esterification reaction with the original and modified 13X zeolites, the activation energies were calculated to be 72.64 and 34.76 $\mathrm{kJ} / \mathrm{mol}$, respectively.

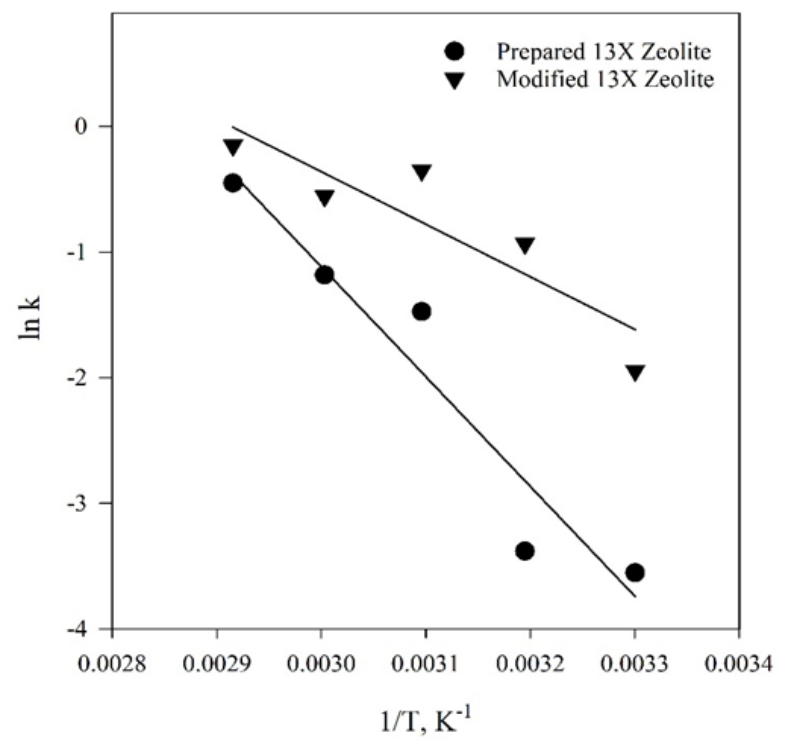

Figure 6. Arrhenius plot of experimental and calculated esterification reaction rate constants over the original and modified 13X zeolites.

\section{Conclusion}

A $13 \mathrm{X}$ zeolite catalyst was successfully prepared from local, invaluable kaolin clay. XRD was used to determine its crystalline structure. The prepared catalyst had 1.74 molar ratio of $\mathrm{Si} / \mathrm{Al}$, and sodium content of 7.441 , which matched well with the values reported for standard 13X zeolite. AFM tests revealed that the average diameter of the original $13 \mathrm{X}$ zeolite was $72.39 \mathrm{~nm}$. The conversion of esterification reaction of OA with ethanol was only $47 \%$ when a 13X zeolite was used as a heterogeneous catalyst. To improve performance of the catalyst, the $\mathrm{Si} / \mathrm{Al}$ ratio was increased by dealuminating the original $13 \mathrm{X}$ zeolite with 0.1 $\mathrm{N}$ citric acid at $75{ }^{\circ} \mathrm{C}$ for $3 \mathrm{~h}$. The modified catalyst had the same XRD pattern as the original one, but showed a higher $\mathrm{Si} / \mathrm{Al}$ ratio (4.72). The AFM tests determined the average diameter to be $113.37 \mathrm{~nm}$. The performance of the modified 13X zeolite was tested via the same OA esterification reaction where it showed remarkable activity and a conversion of $73 \%$. LHHW kinetic models were employed to fit the experimental kinetic data of the heterogeneous catalytic reactions. The activation energies were determined to be 72.64 and $34.76 \mathrm{~kJ} / \mathrm{mol}$ for the esterification reaction with the original and modified 13X zeolites, respectively. The lower activation energy observed when the modified catalyst was used indicates that the reaction became less temperature sensitive. The mean rate for the esterification reaction over the original $13 \mathrm{X}$ zeolite was 0.0022 , while a slightly better rate of 0.0036 was observed when the modified 13X zeolite was employed. Our results indicate that treating the original $13 \mathrm{X}$ zeolite catalyst with citric acid did not destroy its crystalline framework, but provided a modified catalyst with a higher $\mathrm{Si} / \mathrm{Al}$ ratio than the original that also increased the esterification reaction rate and achieved higher OA conversion.

Table 4. Surface reaction rate constants and adsorption equilibrium constants at different reaction temperatures obtained from model Equation (24) for the modified 13X zeolite.

\begin{tabular}{cccccccc}
\hline Temperature (K) & $\begin{array}{c}k_{\mathrm{s}} \\
\text { (g cat/L.mol.s) }\end{array}$ & $K_{\mathrm{S}}$ & $K_{\mathrm{OA}}$ & $K_{\mathrm{EtOH}}$ & $K_{\mathrm{EO}}$ & $K_{\mathrm{W}}$ & $\mathrm{R}^{2}$ \\
\hline 303 & 0.1429 & 21.17 & 0.32 & 0.08 & 0.18 & 31.30 & 0.9325 \\
313 & 0.3933 & 24.79 & 0.32 & 0.08 & 0.22 & 31.30 & 0.8290 \\
323 & 0.7042 & 17.18 & 0.37 & 0.08 & 0.08 & 31.30 & 0.6983 \\
333 & 0.5731 & 16.58 & 0.42 & 0.09 & 0.06 & 31.30 & 0.9890 \\
343 & 0.8583 & 14.56 & 0.30 & 0.08 & 0.06 & 31.39 & 0.8415 \\
\hline
\end{tabular}




\section{References}

[1] Hatti, M. (2019). Renewable Energy for Smart and Sustainable Cities: Artificial Intelligence in Renewable Energetic Systems (1st ed.). Springer International Publishing. DOI: 10.1007/978-3-030-04789-4.

[2] Yesilyurt, M.K., Arslan, M., Eryilmaz, T. (2018). Application of response surface methodology for the optimization of biodiesel production from yellow mustard (Sinapis alba L.) seed oil. International Journal of Green Energy, $\quad 16(1), \quad 60-71$. D O I : 10.1080/15435075.2018.1532431.

[3] Srivastava, N., Srivastava, M., Mishra, P.K., Upadhyay, S.N., Ramteke, P.W., Gupta, V.K. (2019). Sustainable Approaches for Biofuels Production Technologies (1st ed.). Springer International Publishing. DOI: 10.1007/978-3319-94797-6.

[4] Arce, P.F., Guimarães, D.H.P., de Aguirre, L.R. (2019). Experimental data and prediction of the physical and chemical properties of biodiesel. Chemical Engineering Communications, 206(10), 1273-1285. DOI: 10.1080/00986445.2018.1555533.

[5] Alismaeel, Z.T., Abbas, A.S., Albayati, T.M., Doyle, A.M. (2018). Biodiesel from batch and continuous oleic acid esterification using zeolite catalysts. Fuel, 234, 170-176. DOI: 10.1016/j.fuel.2018.07.025.

[6] Chozhavendhan, S., Vijay Pradhap Singh, M., Fransila, B., Praveen Kumar, R., Karthiga Devi, G. (2020). A review on influencing parameters of biodiesel production and purification processes. Current Research in Green and Sustainable Chemistry, 1-2, 1-6. DOI: 10.1016/j.crgsc.2020.04.002.

[7] Wang, A., Li, H., Zhang, H., Pan, H., Yang, S. (2018). Efficient catalytic production of biodiesel with acid-base bifunctional rod-like Ca$\mathrm{B}$ oxides by the sol-gel approach. Materials, 12(1), 1-14. DOI: 10.3390/ma12010083.

[8] Buchori, L., Istadi, I., Purwanto, P. (2016). Advanced chemical reactor technologies for biodiesel production from vegetable oils - A review. Bulletin of Chemical Reaction Engineering \& Catalysis, 11(3), 406-430. DOI: 10.9767/bcrec.11.3.490.406-430.

[9] Estevez, R., Aguado-Deblas, L., Bautista, F.M., Luna, D., Luna, C., Calero, J., Romero, A.A. (2019). Biodiesel at the crossroads: A critical review. Catalysts, 9(12), 1-38. DOI: 10.3390/catal9121033.

[10] Elgharbawi, A.S., Sadik, W.A., Sadek, O.M., Kasaby, M.A. (2021). A review on biodiesel feedstocks and production technologies. Journal of the Chilean Chemical Society, 66(1), 5098-5109. DOI: 10.4067/S071797072021000105098 .
[11] Faruque, M.O., Razzak, S.A., Hossain, M.M. (2020). Application of heterogeneous catalysts for biodiesel production from microalgal oila review. Catalysts, 10(9), 1-25. DOI: 10.3390/catal10091025.

[12] Ramos, M., Dias, A.P.S., Puna, J.F., Gomes, J., Bordado, J.C. (2019). Biodiesel production processes and sustainable raw materials. Energies, $12(23), \quad 1-30$. D O I : 10.3390/en12234408.

[13] Abbas, A.S., Abbas, S.M. (2013). Kinetic study and simulation of oleic acid esterification in different type of reactors. Iraqi Journal of Chemical and Petroleum Engineering, 14(2), 13-20.

[14] Sun, K., Lu, J., Ma, L., Han, Y., Fu, Z., Ding, J. (2015). A comparative study on the catalytic performance of different types of zeolites for biodiesel production. Fuel, 158, 848-854. DOI: 10.1016/j.fuel.2015.06.048.

[15] Abbas, A.S., Abbas, R.N. (2013). Kinetic study and simulation of oleic acid esterification over prepared $\mathrm{NaY}$ zeolite catalyst. Iraqi Journal of Chemical and Petroleum Engineering, 14(4), 35-43.

[16] Doyle, A.M., Albayati, T.M., Abbas, A.S., Alismaeel, Z.T. (2016). Biodiesel production by esterification of oleic acid over zeolite Y prepared from kaolin. Renewable Energy, 97, 19-23. DOI: 10.1016/j.renene.2016.05.067.

[17] Fawaz, E.G., Salam, D.A., Pinard, L., Daou, T.J. (2019). Study on the catalytic performance of different crystal morphologies of HZSM-5 zeolites for the production of biodiesel: A strategy to increase catalyst effectiveness. Catalysis Science and Technology, 9(19), 5456-5471. DOI: 10.1039/c9cy01427f.

[18] Silva, F.M.N., Lima, E.G., Barbosa, T.L.A., Rodrigues, M.G.F. (2019). Evaluation of catalysts Mordenite and $\mathrm{MoO}_{3} /$ mordenite in the production of biodiesel. Materials Science Forum, $958, \quad 11-16$. D O I : 10.4028/www.scientific.net/MSF.958.11.

[19] Doyle, A.M., Alismaeel, Z.T., Albayati, T.M., Abbas, A.S. (2017). High purity FAU-type zeolite catalysts from shale rock for biodiesel production. Fuel, 199, 394-402. DOI: 10.1016/j.fuel.2017.02.098.

[20] Dal Pozzo, D.M., Azevedo Dos Santos, J.A., Júnior, E.S., Santos, R.F., Feiden, A., Melegari De Souza, S.N., Burgardt, I. (2019). Free fatty acids esterification catalyzed by acid Faujasite type zeolite. RSC Advances, 9, 4900-4907. DOI: 10.1039/c8ra10248a. 
[21] Santos, N.A.V., Lopes, J.M.F.M., Magriotis, Z.M., Ribeiro, M.F., Vieira, S.S., Fernandes, A., Graça, I. (2017). Production of biodiesel using HZSM-5 zeolites modified with citric acid and $\mathrm{SO}_{4}{ }^{2-} / \mathrm{La}_{2} \mathrm{O}_{3}$. Catalysis Today, 279, 267-273. DOI: 10.1016/j.cattod.2016.04.014.

[22] Gangil, S., Dhakar, V.S., Parihar, Y. (2017). Synthesis of Biodiesel from Karanja Oil Using Modified Mordenite as a Heterogeneous Catalyst. Biofuels and Bioenergy (BICE2016), 1525. DOI: 10.1007/978-3-319-47257-7.

[23] Lemoine, G. (2013). Comparison of Different Types of Zeolites Used as Solid Acid Catalysts in the Transesterification Reaction of Jatropha-Type Oil for Biodiesel Production. Worcester Polytechnic Institute.

[24] Ravi, M., Sushkevich, V.L., van Bokhoven, J.A. (2020). Towards a better understanding of Lewis acidic aluminium in zeolites. Nature Materials, 19(10), 1047-1056. DOI: 10.1038/s41563-020-0751-3.

[25] Sánchez, I., de Soto, I.S., Casas, M., Vigil de la Villa, R., García-Giménez, R. (2020). Evolution of metakaolin thermal and chemical activation from natural kaolin. Minerals, 10(6), 1-17. DOI: $10.3390 / \min 10060534$.

[26] Ugal, J.R., Mustafa, M., Abdulhadi, A.A. (2008). Preparation of zeolite type 13X from locally available raw materials. Iraqi Journal of Chemical and Petroleum Engineering, 9(1), 51-56.

[27] Alshahidy, B.A., Abbas, A.S. (2020). Preparation and modification of $13 \mathrm{X}$ zeolite as a heterogeneous catalyst for esterification of oleic acid. AIP Conference Proceedings, 2213(1), 020167-1-020167-7. DOI: 10.1063/5.0000171.

[28] Treacy, M.M.J., Higgins, J.B. (2007). Collection of Simulated XRD Powder Patterns for Zeolites (7th ed.). Amsterdam: Elsevier Science.

[29] Cheng, X., Wang, J., Guo, J., Long, Y. (2008). Binder-free ZSM-5 zeolite catalysts modified with framework dealumination. Acta Chimica Sinica, 66(19), 2099-2106.
[30] Breck, D.W. (1974). Zeolite Molecular Sieves: Structure Chemistry and Use. John Wiley \& Sons.

[31] Xu, R., Pang., W. (2004). Chemistry of Molecular Sieve and Material. Science Publishing Company.

[32] Yang, S., Meng., C. (2004). Study on mordenites treated by hydrochloric and oxalic acid and adsorption capacity. Liaoning Chem. Ind., 33(3), 125-126.

[33] Rahnejat, H. (2010). Tribology and Dynamics of Engine and Powertrain: Fundamentals, Applications and Future Trends. Woodhead Publishing.

[34] Liang, H., Totten, G.E. (2004). Surface Modification and Mechanisms: Friction, Stress, and Reaction Engineering (1st ed.). CRC Press.

[35] Myers, N.O. (1962). Characterization of surface roughness. Wear, 5(3), 182-189. DOI: 10.1016/0043-1648(62)90002-9.

[36] Tao, Y., Kanoh, H., Abrams, L., Kaneko, K. (2006). Mesopore-modified zeolites: preparation, characterization, and applications. Chemical Reviews, 106(3), 896-910. DOI: 10.1021/cr040204o.

[37] Li, J., Liu, H., An, T., Yue, Y., Bao, X. (2017). Carboxylic acids to butyl esters over dealuminated-realuminated beta zeolites for removing organic acids from bio-oils. RSC Advances, 7(54), $33714-33725$. DOI: 10.1039/C7RA05298G.

[38] Rase, H.F. (2000). Handbook of Commercial Catalysts: Heterogeneous Catalysts. CRC Press.

[39] Zhang, Y., Ma, L., Yang, J. (2004). Kinetics of esterification of lactic acid with ethanol catalyzed by cation-exchange resins. Reactive and Functional Polymers, 61(1), 101-114. DOI: 10.1016/j.reactfunctpolym.2004.04.003.

[40] Levenspiel, O. (1999). Chemical Reaction Engineering (3rd ed.). John Wiley \& Sons. 